УДК 669.054 .8

В.Д. Вернигора, старший викладач, vernyhora.viktor@gmail.com

Дніпровський державний технічний університет, м. Кам'янське

\title{
МАТЕМАТИЧНА МОДЕЛЬ ПРОЦЕСУ МИЙКИ ШЛІФУВАЛЬНОГО ШЛАМУ
}

Побудовано математичну модель процесу мийки шліфувального шламу в синтетичному миючому розчині. Дана модель дає можливість визначати кількість масла, яке переходить в миючий розчин.

Ключові слова: шліфувальний шлам, миючий розчин, масло,математична модель.

A mathematical model of grinding mud sink process in a synthetic washing solution was constructed. This model makes it possible to determine the amount of oil that goes into the washing solution.

Keywords: grinding sludge, cleaning solution, oil, mathematical model.

\section{Постановка проблеми}

Триваюче забруднення природного середовища твердими, рідкими і газоподібними відходами виробництва і споживання, що викликають деградацію навколишнього середовища, останнім часом залишаються найгострішою екологічною проблемою, має пріоритетне соціальне і економічне значення.

Незважаючи на успіхи в розробці і впровадженні ресурсозберігаючих технологій, у багатьох галузях промисловості триває накопичення металовмісних відходів.

На підприємствах машинобудування, особливо на підшипникових заводах, щомісяця утворюються тисячі тонн металовмісних шламів.

Особливу проблему становлять шліфувальні шлами, які є конгломератом металевих частинок з вкрапленнями абразиву, просочені МОР (мастильно-охолоджуючою рідиною), маслами. У зв'язку зі значним вмістом в шліфувальних шламах не металевих включень, масел і МОР, вони не можуть бути утилізовані без попередньої переробки.

Для того щоб якісно провести поділ твердих частинок металу і абразиву, необхідно відмити їх від масла і МОР.

Авторами [1] розроблений технологічний процес і комплексна система обладнання для вилучення металевих частинок 3 шламів абразивної обробки металів. Проведено дослідження процесу мийки шламу абразивної обробки металів [2].

\section{Аналіз останніх досліджень і публікацій}

3 метою вирішення поставленого завдання були використані матеріали, методології і та підходи, що містяться в роботах [1-3].

\section{Формулювання мети дослідження} бки металів.

Метою роботи є побудова математичної моделі процесу мийки шламу абразивної обро-

\section{Виклад основного матеріалу}

У роботі поставлено завдання про визначення кількості мінерального мастила И-20, яке переходить у миючий розчин «Лабомід» у процесі мийки шламу абразивної обробки металів. Завдання вирішувалося знаходженням умовного мінімуму функції відгуку для кількості забруднення $G(\tau)$. Для одержання зазначеної функції проведений аналіз експериментальних даних процесу мийки шламу.

У математичній постановці задачі у якості змінних прийняті наступні фактори: $M_{\mathrm{M}}$ - кількість масла И-20 в шламі, (кг); $C_{\mathrm{p}}$ - концентрація миючого розчину $\left(\kappa г / \mathrm{M}^{3}\right) ; T$ - температура миючого розчину $\left({ }^{\circ} \mathrm{C}\right) ; \tau$ - час мийки шламу (сек). 
Для побудови математичної моделі залежності кількості забруднення $G=f\left(M_{\mathcal{M}}, C_{p}, T, \tau\right)$ (кг), яке переноситься з боку шламу абразивної обробки металів у миючий розчин від зазначених вище факторів використовується методика планування експерименту.

Загальна кількість досліджень у матриці центрального композиційного ортогонального плану при $\kappa=4$ факторах склала $[4,5]$ :

$$
N=2^{\kappa}+2 \kappa+n_{0}=2^{4}+2 \cdot 4+7=31,
$$

де $n_{0}$ - кількість експериментів в центрі плану з нульовими координатами.

Прийняті при дослідженні рівні і інтервали варіювання факторів наведені у таблиці 1.

Таблиия 1. Рівні і інтервали варіювання факторів

\begin{tabular}{|c|c|c|c|c|c|c|c|c|}
\hline & \multirow[b]{2}{*}{ Фактори } & \multirow{2}{*}{ 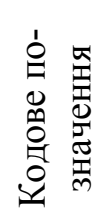 } & \multirow{2}{*}{ 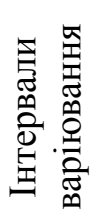 } & \multicolumn{5}{|c|}{ Рівні факторів } \\
\hline $\begin{array}{l}5 \\
0 \\
0 \\
0 \\
01 \\
2\end{array}$ & & & & $-1,414$ & -1 & 0 & +1 & $+1,414$ \\
\hline 1 & $\begin{array}{c}\mathcal{M}_{M} \text { - кількість масла } \\
\text { в шламі, кг }\end{array}$ & $x_{1}$ & 10 & 105,86 & 100 & 110 & 120 & 124,14 \\
\hline 2 & $\begin{array}{c}C_{\mathrm{p}}-\text { концентрація } \\
\text { миючого розчину, } \\
\text { кг } / \mathrm{M}^{3}\end{array}$ & $x_{2}$ & 5 & 7,93 & 10 & 15 & 20 & 22,07 \\
\hline 3 & $\begin{array}{c}T \text { - температура ми- } \\
\text { ючого розчину, }{ }^{\circ} \mathrm{C}\end{array}$ & $x_{3}$ & 10 & 20,86 & 25 & 35 & 45 & 49,14 \\
\hline 4 & $\begin{array}{l}(\tau) \text { - час мийки } \\
\text { шламу, сек. }\end{array}$ & $x_{4}$ & 180 & 105,48 & 180 & 360 & 540 & 614,52 \\
\hline
\end{tabular}

Матриця планування і результати дослідження наведені у таблиці 2.

По результатам досліджень, виконаних у відповідності з прийнятим планом експерименту, можна оцінити коефіцієнти рівняння регресії виду:

$$
\begin{aligned}
& y=b_{0}+b_{1} x_{1}+b_{2} x_{2}+b_{3} x_{3}+b_{4} x_{4}+b_{12} x_{1} x_{2}+b_{13} x_{1} x_{3}++b_{14} x_{1} x_{4}+b_{23} x_{2} x_{3}+b_{24} x_{2} x_{4}+ \\
& +b_{34} x_{3} x_{4}+b_{11} x_{1}^{2}+b_{22} x_{2}^{2}+b_{33} x_{3}^{2}+b_{44} x_{4}^{2} .
\end{aligned}
$$

Визначаємо коефіцієнти рівняння при $\kappa=4$ по формулам [4,5]:

$b_{0}=3,823 ; b_{1}=0,0743 ; b_{2}=0,4282 ; b_{3}=0,3404 ; b_{4}=-1,036 ; b_{12}=0,0594 ; b_{13}=-0,0198$;

$b_{14}=-0,0594 ; b_{23}=1,3035 ; b_{24}=-0,02288 ; b_{34}=-0,227 ; b_{11}=0,912 ; b_{22}=0,863 ; b_{33}=0,845$;

$b_{44}=0,833$.

Дисперсію $S_{y}^{2}$ відтворюваності визначаємо по результатам досліджень в центрі плану.

Для розрахунку $S_{y}^{2}$ склали додаткову таблицю (табл. 3).

Дисперсії, що характеризують помилки в визначенні коефіцієнтів рівняння регресії при $\kappa=4$, вичислили по формулам $[4,5]$ :

$$
S^{2}\left\{b_{0}\right\}=0,0625 ; \quad S^{2}\left\{b_{i}\right\}=0,0219 ; S^{2}\left\{b_{i l}\right\}=0,0394 ; S^{2}\left\{b_{i i}\right\}=0,0221 .
$$

Визначаємо довірчі інтервали для коефіцієнтів рівняння регресії:

$$
\begin{array}{cc}
\Delta b_{0}= \pm t \cdot S\left\{b_{0}\right\}= \pm 0,6427 ; & \Delta b_{i}= \pm t \cdot S\left\{b_{i}\right\}= \pm 0,3801 ; \\
\Delta b_{i l}= \pm t \cdot S\left\{b_{i l}\right\}= \pm 0,51001 ; & \Delta b_{i i}= \pm t \cdot S\left\{b_{i i}\right\}= \pm 0,3816 .
\end{array}
$$

де $\pm t=2,57$ - табличне значення критерію Стьюдента при п'ятипроцентному рівні значимості і числом ступеню свободи $f=5$. 
Таблиия 2. Матриця планування і результати дослідів

\begin{tabular}{|c|c|c|c|c|c|c|c|c|c|c|c|c|c|c|c|c|}
\hline № & $x_{0}$ & $x_{1}$ & $x_{2}$ & $x_{3}$ & $x_{4}$ & $x_{1} x_{2}$ & $x_{1} x_{3}$ & $x_{1} x_{4}$ & $x_{2} x_{3}$ & $x_{2} x_{4}$ & $x_{3} x_{4}$ & $x_{1}^{2}$ & $x_{2}^{2}$ & $x_{3}^{2}$ & $x_{4}^{2}$ & $y$ \\
\hline 1 & 1 & -1 & \begin{tabular}{l|l|}
-1 \\
\end{tabular} & \begin{tabular}{l|}
-1 \\
\end{tabular} & -1 & 1 & 1 & 1 & 1 & 1 & 1 & 1 & 1 & 1 & 1 & 7,74 \\
\hline 2 & 1 & 1 & -1 & -1 & -1 & \begin{tabular}{l|}
-1 \\
\end{tabular} & -1 & -1 & 1 & 1 & 1 & 1 & 1 & 1 & 1 & 7,82 \\
\hline 3 & 1 & -1 & 1 & -1 & -1 & -1 & 1 & 1 & -1 & -1 & 1 & 1 & 1 & 1 & 1 & 6,69 \\
\hline 4 & 1 & 1 & 1 & -1 & -1 & 1 & -1 & -1 & -1 & -1 & 1 & 1 & 1 & 1 & 1 & 7,16 \\
\hline 5 & 1 & -1 & -1 & 1 & -1 & 1 & -1 & 1 & -1 & 1 & -1 & 1 & 1 & 1 & 1 & 6,97 \\
\hline 6 & 1 & 1 & -1 & 1 & -1 & -1 & 1 & -1 & -1 & 1 & -1 & 1 & 1 & 1 & 1 & 7,03 \\
\hline 7 & 1 & -1 & 1 & 1 & -1 & -1 & -1 & 1 & 1 & -1 & -1 & 1 & 1 & 1 & 1 & 9,48 \\
\hline 8 & 1 & 1 & 1 & 1 & -1 & 1 & 1 & -1 & 1 & -1 & -1 & 1 & 1 & 1 & 1 & 9,83 \\
\hline 9 & 1 & -1 & -1 & -1 & 1 & 1 & 1 & -1 & 1 & -1 & -1 & 1 & 1 & 1 & 1 & 6,07 \\
\hline 10 & 1 & 1 & -1 & -1 & 1 & -1 & -1 & 1 & 1 & -1 & -1 & 1 & 1 & 1 & 1 & 6,18 \\
\hline 11 & 1 & -1 & 1 & -1 & 1 & -1 & 1 & -1 & -1 & 1 & -1 & 1 & 1 & 1 & 1 & 5,04 \\
\hline 12 & 1 & 1 & 1 & -1 & 1 & 1 & -1 & 1 & -1 & 1 & -1 & 1 & 1 & 1 & 1 & 5,12 \\
\hline 13 & 1 & -1 & -1 & 1 & 1 & 1 & -1 & -1 & -1 & -1 & 1 & 1 & 1 & 1 & 1 & 4,58 \\
\hline 14 & 1 & 1 & -1 & 1 & 1 & -1 & 1 & 1 & -1 & -1 & 1 & 1 & 1 & 1 & 1 & 4,63 \\
\hline 15 & 1 & -1 & 1 & 1 & 1 & -1 & -1 & -1 & 1 & 1 & 1 & 1 & 1 & 1 & 1 & 7,26 \\
\hline 16 & 1 & 1 & 1 & 1 & 1 & 1 & 1 & 1 & 1 & 1 & 1 & 1 & 1 & 1 & 1 & 7,32 \\
\hline 17 & 1 & 1,414 & 0 & 0 & 0 & 0 & 0 & 0 & 0 & 0 & 0 & 2 & 0 & 0 & 0 & 6,01 \\
\hline 18 & 1 & $-1,414$ & 0 & 0 & 0 & 0 & 0 & 0 & 0 & 0 & 0 & 2 & 0 & 0 & 0 & 5,85 \\
\hline 19 & 1 & 0 & 1,414 & 0 & 0 & 0 & 0 & 0 & 0 & 0 & 0 & 0 & 2 & 0 & 0 & 6,25 \\
\hline 20 & 1 & 0 & \begin{tabular}{|l|}
$-1,414$ \\
\end{tabular} & 0 & 0 & 0 & 0 & 0 & 0 & 0 & 0 & 0 & 2 & 0 & 0 & 5,06 \\
\hline 21 & 1 & 0 & 0 & 1,414 & 0 & 0 & 0 & 0 & 0 & 0 & 0 & 0 & 0 & 2 & 0 & 6,1 \\
\hline 22 & 1 & 0 & 0 & $-1,414$ & 0 & 0 & 0 & 0 & 0 & 0 & 0 & 0 & 0 & 2 & 0 & 5,02 \\
\hline 23 & 1 & 0 & 0 & 0 & 1,414 & 0 & 0 & 0 & 0 & 0 & 0 & 0 & 0 & 0 & 2 & 4,007 \\
\hline 24 & 1 & 0 & 0 & 0 & $-1,414$ & 0 & 0 & 0 & 0 & 0 & 0 & 0 & 0 & 0 & \begin{tabular}{l|l}
2 \\
\end{tabular} & 6,98 \\
\hline 25 & 1 & 0 & 0 & 0 & 0 & 0 & 0 & 0 & 0 & 0 & 0 & 0 & 0 & 0 & 年 & 4,761 \\
\hline 26 & 1 & 0 & 0 & 0 & 0 & 0 & 0 & 0 & 0 & 0 & 0 & 0 & 0 & 0 & 0 & 4,018 \\
\hline 27 & 1 & 0 & 0 & 0 & 0 & 0 & 0 & 0 & 0 & 0 & 0 & 0 & 0 & 0 & 0 & 4,9 \\
\hline 28 & 1 & 0 & 0 & 0 & 0 & 0 & 0 & 0 & 0 & 0 & 0 & 0 & 0 & 0 & 0 & 3,018 \\
\hline 29 & 1 & 0 & 0 & 0 & 0 & 0 & 0 & 0 & 0 & 0 & 0 & 0 & 0 & 0 & 0 & 4,083 \\
\hline 30 & 1 & 0 & 0 & 0 & 0 & 0 & 0 & 0 & 0 & 0 & 0 & 0 & 0 & 0 & 0 & 4,79 \\
\hline 31 & 1 & 0 & 0 & 0 & 0 & 0 & 0 & 0 & 0 & 0 & 0 & 0 & 0 & 0 & 0 & 4,018 \\
\hline
\end{tabular}

Таблиия 3. Допоміжна таблиця для розрахунку $s_{y}^{2}$

\begin{tabular}{|c|c|c|c|c|c|}
\hline $\begin{array}{l}\text { Номер дос- } \\
\text { лідження }\end{array}$ & $y_{j}$ & $\bar{y}_{j}$ & $y_{j}-\bar{y}_{j}$ & $\left(y_{j}-\bar{y}_{j}\right)^{2}$ & $s_{y}^{2}$ \\
\hline 25 & 4,7615 & \multirow{7}{*}{$\begin{array}{l}\bar{y}=\frac{\sum_{z=1}^{n_{0}} y_{z}}{n_{0}}= \\
=\frac{29,5985}{7}= \\
=4,2269\end{array}$} & 0,5346 & 0,28576 & \multirow{8}{*}{$\begin{array}{l}s_{y}^{2}=\frac{\sum_{j=1}^{n_{0}}\left(y_{j}-\bar{y}_{j}\right)^{2}}{n_{0}-1} \\
=\frac{2,62536}{7-1}=0,43756\end{array}$} \\
\hline 26 & 4,018 & & $-0,2089$ & 0,04365 & \\
\hline 27 & 4,91 & & 0,6731 & 0,45302 & \\
\hline 28 & 3,018 & & $-1,2089$ & 1,4615 & \\
\hline 29 & 4,083 & & $-0,1439$ & 0,02072 & \\
\hline 30 & 4,79 & & 0,5631 & 0,31705 & \\
\hline \multirow[t]{2}{*}{31} & 4,018 & & $-0,2089$ & 0,04365 & \\
\hline & $\sum_{j=1}^{n_{0}} y_{j}=29,598$ & & & $\begin{array}{l}s_{E}=\sum_{j=1}^{n_{0}}\left(y_{j}-\bar{y}_{j}\right)^{2}= \\
=2,62536\end{array}$ & \\
\hline
\end{tabular}

Коефіцієнт $b_{24}$ менше довірчого інтервалу, тому його можна признати статистично не значимим і виключити із рівняння регресії. Після виключення незначущого коефіцієнту, рівняння (2) прийме вид:

$$
\begin{aligned}
& y=b_{0}+b_{1} x_{1}+b_{2} x_{2}+b_{3} x_{3}+b_{4} x_{4}+b_{12} x_{1} x_{2}+b_{13} x_{1} x_{3}++b_{14} x_{1} x_{4}+b_{23} x_{2} x_{3}+ \\
& +b_{34} x_{3} x_{4}+b_{11} x_{1}^{2}+b_{22} x_{2}^{2}+b_{33} x_{3}^{2}+b_{44} x_{4}^{2} .
\end{aligned}
$$


Адекватність отриманої моделі перевіряємо по критерію Фішера.

Знаходимо дисперсію адекватності за формулою:

$$
s_{a \partial}^{2}=\frac{s_{R}-s_{y}}{N-\kappa-\left(n_{0}-1\right)},
$$

Визначаємо суму квадратів відхилень розрахункових значень $\hat{y}_{p}$ функції відгуку від експериментальних $y_{\text {on }}$.

Для обчислення $s_{R}$ складемо допоміжну таблицю 4.

Таблиияя 4. Допоміжна таблиця для розрахунку $s_{R}$

\begin{tabular}{|c|c|c|c|c|c|}
\hline $\begin{array}{c}\text { Номер дослі- } \\
\text { дження }\end{array}$ & $y_{\text {on }}$ & $\hat{y}_{p}$ & $y_{\text {on }}-\hat{y}_{p}$ & $\varepsilon=\frac{y_{o n}-y_{p}}{y_{o n}} \cdot 100 \%$ & $\left(y_{o n}-\hat{y}_{p}\right)^{2}$ \\
\hline 1 & 7,74 & 8,5263 & $-0,7863$ & $-0,10159$ & 0,61829 \\
\hline 2 & 7,82 & 8,7145 & $-0,8945$ & $-0,11439$ & 0,800233 \\
\hline 3 & 6,69 & 6,6567 & 0,0332 & 0,00497 & 0,001105 \\
\hline 4 & 7,16 & 7,0826 & 0,0773 & 0,010803 & 0,005982 \\
\hline 5 & 6,97 & 7,0933 & $-0,1233$ & $-0,0177$ & 0,015213 \\
\hline 6 & 7,03 & 7,2023 & $-0,1723$ & $-0,02452$ & 0,029709 \\
\hline 7 & 9,48 & 10,437 & $-0,9578$ & $-0,10104$ & 0,917532 \\
\hline 8 & 9,83 & 10,7846 & $-0,9545$ & $-0,09711$ & 0,911187 \\
\hline 9 & 6,07 & 7,0263 & $-0,9563$ & $-0,15755$ & 0,914605 \\
\hline 10 & 6,18 & 6,9769 & $-0,7969$ & $-0,12895$ & 0,635103 \\
\hline 11 & 5,04 & 5,1567 & $-0,1167$ & 0,02317 & 0,013639 \\
\hline 12 & 5,12 & 5,3450 & $-0,2250$ & $-0,04395$ & 0,050638 \\
\hline 13 & 4,58 & 4,6859 & $-0,1059$ & $-0,02313$ & 0,011225 \\
\hline 14 & 4,63 & 4,5573 & 0,0726 & 0,015699 & 0,005284 \\
\hline 15 & 7,26 & 8,0304 & $-0,7704$ & $-0,10613$ & 0,593651 \\
\hline 16 & 7,32 & 8,1395 & $-0,8195$ & $-0,11196$ & 0,671598 \\
\hline 17 & 6,01 & 5,7512 & 0,2587 & 0,043057 & 0,066962 \\
\hline 18 & 5,85 & 5,5410 & 0,3089 & 0,05281 & 0,095443 \\
\hline 19 & 6,25 & 6,1525 & 0,0974 & 0,015584 & 0,009487 \\
\hline 20 & 5,06 & 4,9417 & 0,1182 & 0,023367 & 0,01398 \\
\hline 21 & 6,1 & 5,9942 & 0,1057 & 0,01733 & 0,011176 \\
\hline 22 & 5,02 & 5,0317 & $-0,012$ & $-0,00233$ & 0,000137 \\
\hline 23 & 4,007 & 4,0237 & $-0,0168$ & $-0,00419$ & 0,000282 \\
\hline 24 & 6,98 & 6,9543 & 0,0256 & 0,003678 & 0,000659 \\
\hline 25 & 4,7615 & 3,8226 & 0,9388 & 0,197168 & 0,881374 \\
\hline 26 & 4,018 & 3,8226 & 0,1953 & 0,04861 & 0,038148 \\
\hline 27 & 4,9 & 3,8226 & 1,0773 & 0,21986 & 1,160608 \\
\hline 28 & 3,018 & 3,8226 & $-0,8046$ & $-0,26663$ & 0,647518 \\
\hline 29 & 4,083 & 3,8226 & 0,2603 & 0,063756 & 0,067764 \\
\hline 30 & 4,79 & 3,8226 & 0,9673 & 0,201945 & 0,935699 \\
\hline 31 & 4,018 & 3,8226 & 0,1953 & 0,04861 & 0,038148 \\
\hline & & & & & $\begin{array}{l}s_{R}=\sum_{j=1}^{31}\left(y_{\text {on }}-y_{p}\right)^{2}= \\
=10,1624\end{array}$ \\
\hline
\end{tabular}


Сумма квадратів $s_{E}$ (див. табл. 3) буде дорівнювати: $s_{E}=2,62536$.

Тоді дисперсія адекватності буде:

$$
\begin{gathered}
s_{a d}^{2}=\frac{10,1624-2,62536}{20-14-(7-1)}=0,68518 . \\
s_{y}^{2}=0,43756 \text { (див. табл. } 3 \text { ). }
\end{gathered}
$$

Критерій Фішера розраховуємо по формулі:

$$
F_{p}=\frac{s_{a d}^{2}}{s_{y}^{2}} .
$$

При розрахунку критерію Фішера повинна виконуватися умова $s_{a d}^{2}>s_{y}^{2}$. В противному випадку необхідно поміняти місцями дисперсії [5].

Визначаємо розрахункове значення критерію Фішера:

$$
F_{p}=\frac{s_{y}^{2}}{s_{a d}^{2}}=\frac{0,68518}{0,43756}=1,5659 .
$$

При п’ятипроцентному рівні значущості і числах ступенів свободи дисперсії адекватності $f_{a d}=N-k^{\prime}-\left(n_{0}-1\right)=31-14-(7-1)=11$ і дисперсії відтворюваності $f_{y}=n_{0}-1=7-1=6$, табличне значення критерію Фішера $F_{T}(0,05 ; 11 ; 6)=3,09$.

Обчислені за рівнянням (3) значення відрізняються від експериментальних на величини, що не перевищують похибку досліду (табл. 4).

Кодовані значення факторів пов'язані з натуральними наступними залежностями:

$$
\begin{gathered}
x_{1}=\frac{M_{M}-110}{10}=0,1 M_{M}-11 ; \\
x_{2}=\frac{C_{p}-15}{5}=0,2 C_{p}-3 ; \\
x_{3}=\frac{T-35}{10}=0,1 T-3,5 ; \\
x_{4}=\frac{\tau-360}{180}=0,0056 \tau-2 .
\end{gathered}
$$

Переходячи від кодованих $\left(x_{1} ; x_{2} ; x_{3} ; x_{4}\right)$ значень факторів до натуральних, $\left(M_{M} ; C_{p} ; T ; \tau\right)$ одержимо залежність кількості забруднення $G_{i}$, що перейшло зі шламу абразивної обробки металів у миючий розчин «Лабомід» від складових (кількості масла в шламі, концентрації і температури миючого розчину, а також від часу мийки шламу).

Підставивши рівняння (6) у рівняння (3) отримуємо адекватну інтерполяційну формулу для обчислення величини $G_{i}$ - кількості масла И-20, яке переходить у миючий розчин за час мийки шліфувального шламу.

\section{Висновки}

Розроблена математична модель процесу мийки шламів абразивної обробки металів в миючому розчині дозволяє визначити кількість мастила, що переходить в миючий розчин при заданих межах часу мийки. Це дозволить оптимізувати процес мийки і мінімізувати габаритні розміри (довжину) мийного жолобу обладнання для переробки шламів абразивної обробки металів.

\section{Список використаної літератури}

1. Вернигора В.Д. Извлечение металлических частиц из шламов абразивной обработки металлов / В.Д. Вернигора, А.Н. Коробочка // Збагачення корисних копалин: Наук. - техн. зб. 2008. - Вип. 32(73). - С. 26-32. 
2. Вернигора В.Д. Исследование процесса мойки твердых частиц шлама абразивной обработки металлов/ В.Д.Вернигора // Механизация производственных процессов рыбного хозяйства, промышленных и аграрных предприятий. Сб. науч. труд. КГМТУ. - Керчь: 2008. Вып. 9. C. $137-140$.

3. Вернигора В.Д. Исследование процесса мойки металлосодержащих шламов/ В.Д. Вернигора, А.Н. Коробочка //«Математичне моделювання». Математичні моделі та алгоритми: Науковий журнал. - Дніпродзержинськ: ДДТУ. - 2015. Випуск 1(32). - С. 52-56.

4. Спиридонов А.А. Планирование эксперимента при исследовании технологических процессов / А.А. Спиридонов // - М.: Машиностроение, 1981. - 184 с.

5. Блохин В.Г. Современный эксперимент: подготовка, проведение, анализ результатов / В.Г. Блохин, О.П. Глудкин, А.И. Гуров, М.Л. Ханин; Под ред. О.П. Глудкина // М.: Радио и связь, 1997. $-232 \mathrm{c}$. 